\title{
COMUNICAÇÃO
}

\section{EFEITO DA TEMPERATURA E DO TEGUMENTO NA GERMINAÇÃO DE SEMENTES DE Calophyllum brasiliense ${ }^{1}$}

\author{
Effect of temperature and coat in the germination of Calophyllum brasiliense seeds ${ }^{1}$
}

\author{
Fernanda Carlota Nery ${ }^{2}$, Amauri Alves de Alvarenga ${ }^{3}$, Cristina Filomena Justo ${ }^{4}$, \\ Sara Dousseau ${ }^{5}$, Carlos Vinício Vieira ${ }^{2}$
}

\begin{abstract}
RESUMO
A crescente demanda por informações de espécies com potencial para serem implantadas em ambientes degradados, torna fundamental o conhecimento fisiológico da germinação de sementes, visando sua exploração mais racional. Objetivou-se neste trabalho, estudar o comportamento da embebição das sementes, determinar a temperatura ótima da germinação e o efeito da retirada de tegumento sobre a germinação de sementes de Calophyllum brasiliense Cambess. O teste de germinação foi realizado em rolos de papel, com quatro repetições de 25 sementes, em delineamento inteiramente casualizado. Os resultados da curva de embebição demonstraram que o envoltório (endocarpo + tegumento) dificulta a absorção de água pela semente. Quanto à temperatura, observouse uma maior germinabilidade nos regimes térmicos de $30^{\circ} \mathrm{C}$ (constante) e $30 / 20^{\circ} \mathrm{C}$ (alternada), sendo que, o maior índice de velocidade de germinação (IVG) também ocorreu a $30^{\circ} \mathrm{C}$. As sementes incubadas a $10^{\circ} \mathrm{C}, 15^{\circ} \mathrm{C}$ e $40^{\circ} \mathrm{C}$ não germinaram. Menores valores de tempo médio de germinação foram observados nos regimes térmicos de $30^{\circ} \mathrm{C}, 30 / 20^{\circ} \mathrm{C}$ e $35^{\circ} \mathrm{C}$. Não foram verificadas diferenças significativas quanto à germinabilidade das sementes com e sem tegumento, porém, o tegumento reduziu a velocidade de germinação.
\end{abstract}

Termos para indexação: Recalcitrante, curva de embebição, guanandi.

\begin{abstract}
Due to the increasing demand for informations about species with potential for being introduced in degraded environment, it is important the physiological knowledge of seeds germination, aiming their rational exploration. The objective of this research was to evaluate the behaviour of seed imbibition, to determine the germination optimum temperature and the effect of coat seeds withdrawing in the germination of Calophyllum brasiliense Cambess. The germination was performed in paper rolls, with four replicates of 25 seeds each, disposed in a complete randomized design. The results of imbibition curve showed that seed-coat has as hindance for the water absorption by seed. In relation to temperature, it was observed a higher germination percentage at $30^{\circ} \mathrm{C}$ (constant) and $30 / 20^{\circ} \mathrm{C}$ (alternate). Higher speed germination index (IVG) was also observed at $30^{\circ} \mathrm{C}$. The seeds incubated at $10^{\circ} \mathrm{C}$, $15^{\circ} \mathrm{C}$ and $40^{\circ} \mathrm{C}$ did not germinate. The lowest values of germination mean time was at $30^{\circ} \mathrm{C}, 30 / 20^{\circ} \mathrm{C}$ and $35^{\circ} \mathrm{C}$. No significative differences were verified in relation to germinability with and without tegument, although the tegument reduced the germination rate.
\end{abstract}

Index terms: Recalcitrant, imbibition, guanandi.

(Recebido em 18 de maio de 2006 e aprovado em 13 de fevereiro de 2007)

O Brasil está entre os países que mais devastam o meio ambiente e os recursos naturais. Situa-se também entre os países com maior diversidade biológica do mundo e, ao mesmo tempo, uma das menos estudadas. Tornamse, por isso, urgentes os estudos para o conhecimento e preservação da sua flora e fauna. No caso particular da germinação das sementes, algumas informações fragmentadas existem para os ecossistemas brasileiros, mas, muito pouco, ao se considerar o potencial biológico que existe para ser descoberto (BORGHETTI, 2000).

A germinação da semente é considerada como a retomada das atividades metabólicas do eixo embrionário, o qual se encontrava paralisado nas fases finais do processo de maturação; porém, quando estimulado por condições ambientais, desenvolve-se, ocorrendo, então, o rompimento do tegumento pela radícula. Essa é uma etapa

${ }^{1}$ Parte da dissertação de mestrado apresentada à Universidade Federal de Lavras pela primeira autora.

²Engenheiros Agrônomos, Doutorandos em Fisiologia Vegetal - Departamento de Biologia/DBI - Universiade Federal de Lavras/UFLA - Cx. P. 3037 37200-000 - Lavras, MG - fernandacarlota@yahoo.com.br; vieiracv@gmail.com

${ }^{3}$ Professor Titular - Departamento de Biologia/DBI - Universiade Federal de Lavras/UFLA - Cx. P. 3037-37200-000 - Lavras, MG - amauriaa@uflanet.com ${ }^{4}$ Doutora em Agronomia - Departamento de Ciências Biológicas e da Saúde/DCBS - Universidade Federal de Mato Grosso/UFMT - Rodovia MT 100, Km 3,5, Campus Universitário - 78698-000 - Pontal do Araguaia, MT - cfjusto@uol.com.br

${ }^{5}$ Engenheira Agrônoma, Mestranda em Agronomia - Departamento de Biologia/DBI - Universiade Federal de Lavras/UFLA - Cx. P. 3037 - $37200-000$ -

Lavras, MG - saradousseau@yahoo.com.br 
crítica do biociclo vegetal pelo fato do processo estar associado a vários fatores de natureza extrínseca (fatores do ambiente físico) e intrínseca, ou seja, a processos fisiometabólicos (BEWLEY \& BLACK, 1994; LABORIAU, 1983; POPINIGIS, 1985; SANTOS, 1999).

Assim como qualquer ser vivo, a temperatura afeta o metabolismo das sementes. Para qualquer processo fisiológico, existem temperaturas limitantes e temperaturas ótimas para a germinação. A temperatura é responsável não somente pela velocidade de germinação como também pelo percentual final de germinação (CARVALHO et al., 2001; FERRAZ-GRANDE \& TAKAKI, 2001; MEDEIROSSILVA et al., 2002; SOCOLOWSKI \& TAKAKI, 2004).

Existem lotes ou sementes que germinam mais rapidamente e outras cuja germinação é mais lenta. Para essas situações, existem medidas que quantificam a germinação sob o ponto de vista cinético, informando o tempo necessário para determinado lote de sementes germinar. Um parâmetro bastante utilizado é o tempo médio de germinação (FERREIRA \& BORGHETTI, 2004).

O processo de embebição das sementes constitui um importante procedimento técnico para auxiliar na identificação da especificidade de dormência, sobretudo quando associado à dureza e à impermeabilidade de tegumento (ALMEIDA, 2001).

A água exerce influência determinante sobre o processo de germinação e sua absorção desempenha efeitos, como o aumento de volume da semente, provocando o rompimento do tegumento, o que vem, posteriormente, facilitar a emergência do eixo embrionário (ou outra estrutura qualquer) do interior da semente (CARVALHO \& NAKAGAWA, 2000).

A espécie Calophyllum brasiliense Cambess., conhecida popularmente como guanandi, é nativa de matas ciliares de quase todo Brasil, principalmente na faixa litorânea. É uma espécie clímax que apresenta regeneração abundante na sombra. Seus frutos são muito procurados pela fauna; além de serem disseminados por hidrocoria. A espécie é indicada, principalmente, para a reposição de mata ciliar em locais sujeitos a inundações periódicas de média a longa duração. A casca e o látex são usados na medicina popular no tratamento de úlcera e diabetes, e na veterinária para fortalecer os tendões dos animais (CARVALHO, 1994). Segundo Flores (2002), a espécie apresenta um embrião grande e bem desenvolvido, endocarpo e testa duros, tegumento delgado e macio, embrião maciço, cotilédones maciços e fundidos, hipocótilo também maciço, radícula pequena e densa, sendo o constituinte de reserva principal das sementes os lipídeos.
Objetivou-se com este trabalho, estudar a embebição das sementes de $C$. brasiliense, determinar a temperatura ótima da germinação e o efeito da retirada de tegumento sobre a germinação de sementes dessa espécie.

O presente trabalho foi conduzido no Laboratório de Crescimento e Desenvolvimento de Plantas, Setor de Fisiologia Vegetal, do Departamento de Biologia da Universidade Federal de Lavras, MG.

Os frutos maduros de C. brasiliense foram coletados na época de dispersão, no período de agosto a outubro de 2004, em árvores matrizes localizadas no município de Carrancas, MG (2129'S e 44³9'W GRM). Posteriormente, os frutos foram despolpados manualmente em laboratório e analisados quanto à germinação e ao vigor.

Para a construção da curva de embebição foram utilizados lotes de diásporos com envoltório (endocarpo+tegumento) e sem envoltório (escarificados manualmente, sendo retirado o endocarpo e o tegumento). Os diásporos foram divididos em três amostras de 10 diásporos, pré-tratados por 15 minutos com suspensão de Benomyl a $0,1 \%(\mathrm{p} / \mathrm{v})$ e cada amostra colocada para germinar em rolos de papel Germitest ${ }^{\circledR}$ umedecido com água destilada (2,5 vezes a massa do papel) e, em seguida, transferidas para a câmara de germinação, a uma temperatura de $30 \pm 2^{\circ} \mathrm{C}$, na ausência de luz. A primeira pesagem foi realizada com os diásporos secos e as demais durante o processo de embebição. Nas primeiras 12 horas de embebição, foram realizadas pesagens a cada 30 minutos e, nas 12 horas subseqüentes, as pesagens foram realizadas de hora em hora e, posteriormente, a cada três horas, até que fosse observado a protrusão radicular. A porcentagem de incremento sobre a massa fresca inicial foi calculada segundo Lima Júnior (2004) e os dados analisados através de regressão polinomial.

Para avaliação do efeito da temperatura sobre a germinação, sementes escarificadas (endocarpo e tegumento retirados manualmente) foram submetidas a diferentes regimes térmicos de $10^{\circ} \mathrm{C}, 15^{\circ} \mathrm{C}, 20^{\circ} \mathrm{C}, 25^{\circ} \mathrm{C}, 30^{\circ} \mathrm{C}$, $35^{\circ} \mathrm{C}$ e $40^{\circ} \mathrm{C}$ (constantes) e $25 / 15^{\circ} \mathrm{C}$ e $30 / 20^{\circ} \mathrm{C}$ (alternadas), na ausência de luz. O substrato utilizado foi o rolo de papel Germitest ${ }^{\circledR}$ umedecido com água destilada $(2,5$ vezes a massa do papel), colocado em béqueres de $250 \mathrm{~mL}$ contendo $50 \mathrm{~mL}$ de água e cobertos com sacos plásticos para uniformizar a umidade no meio de germinação. Foram utilizadas câmaras de germinação do tipo B.O.D para temperaturas alternadas e do tipo Mangelsdorf para as temperaturas constantes de $20^{\circ} \mathrm{C} \mathrm{a} 40^{\circ} \mathrm{C}$ e refrigerador para as temperaturas de $10^{\circ} \mathrm{C}$ e $15^{\circ} \mathrm{C}$, com umidade relativa de aproximadamente $100 \%$ (BRASIL, 1992). As sementes submetidas às temperaturas de $10^{\circ} \mathrm{C}, 15^{\circ} \mathrm{C}$ e $40^{\circ} \mathrm{C}$, foram 
transferidas após 30 dias nessas condições para a temperatura de $30^{\circ} \mathrm{C}$. As sementes foram pré-tratadas com suspensão de Benomyl a $0,1 \%(\mathrm{p} / \mathrm{v})$. As avaliações de germinação foram realizadas diariamente, utilizando-se, como parâmetro de germinação, a protrusão da radícula e cerca de $5 \mathrm{~mm}$ de alongamento do hipocótilo. Foram utilizadas 4 repetições de 25 sementes em cada tratamento.

O índice de velocidade de germinação (IVG) foi obtido juntamente com o teste de germinação, sendo as avaliações realizadas diariamente a partir da protrusão da radícula. Para o cálculo do IVG foi empregada a equação proposta por Maguire (1962).

O tempo médio de germinação $(\mathrm{Tm})$ foi calculado com base nos dados obtidos no teste de germinação e calculado segundo a expressão proposta por Santana \& Ranal (2004):

$$
\bar{t}=\frac{\sum_{i=1}^{k} n_{i} t_{i}}{\sum_{i=1}^{k} n_{i}}
$$

em que:

$t_{i}$ : tempo entre o início do experimento e a $i$-ésima observação (dia ou hora);

$n_{i}$ : número de sementes que germinam no tempo $t_{i}$ (não o número acumulado, mas, o número referido para a $i$-ésima observação);

$k:$ último dia da observação.

Para avaliação do efeito do tegumento sobre a germinação a diferentes temperaturas, utilizou-se sementes com e sem tegumento as quais foram submetidas às temperaturas constantes de $20^{\circ} \mathrm{C} ; 25^{\circ} \mathrm{C}$ e $30^{\circ} \mathrm{C}$, na ausência de luz. O substrato, o tratamento pré-germinativo e as câmaras de germinação e os critérios de germinação foram os mesmos descritos no experimento anterior. Os dados foram analisados utilizando um esquema fatorial $2 \times 3$ (2 tipos de semente $\mathrm{x} 3$ temperaturas). Foram utilizadas 4 repetições de 25 sementes em cada tratamento.

Os ensaios foram conduzidos seguindo-se o delineamento inteiramente casualizado e os dados obtidos analisados pelo software estatístico SAS ${ }^{\circledR}$ (SAS INSTITUTE, 1990) e as médias comparadas pelo teste Tukey, a 5\% de probabilidade.

O processo de absorção de água pelas sementes evolui de acordo com o padrão trifásico, proposto por Bewley \& Black (1978), sendo a Fase I, caracterizada pela rápida transferência de água do substrato para a semente, graças à diferença acentuada entre os potenciais hídricos.
Tanto para os diásporos com e sem envoltório, essa primeira fase de captação de água ocorreu durante as primeiras 17 horas, para os diásporos com envoltório a embebição neste período, provavelmente, ocorreu através desse revestimento (Figura 1). Nesta fase, surgem os primeiros sinais de reativação do metabolismo, com aumento acentuado da atividade respiratória e liberação de energia para a germinação, ativação de enzimas e síntese de proteínas a partir do RNAm armazenado ao final do processo de maturação (FERREIRA \& BORGHETTI, 2004).

Lima Júnior (2004), estudando sementes de Cupania vernalis Cambess., com e sem tegumento, verificou que a maior velocidade de absorção de água ocorreu nas primeiras 25 horas de embebição. Os resultados encontrados para Ocotea odorifera (Vell.) Rohwer por Cetnarski Filho \& Nogueira (2005), são similares aos obtidos nesses trabalhos, em que afirmam que nas seis primeiras horas os diásporos com envoltório tiveram aumento no incremento de absorção de água, possivelmente, também, em conseqüência da absorção pelo próprio envoltório.

As reduções drásticas da velocidade de hidratação e o aumento da intensidade de respiração caracterizam a Fase II. Nos diásporos sem envoltório, a Fase II, aparentemente, durou até cerca de 90 horas. Pela Figura 1, nota-se, ainda, que o processo de embebição nos diásporos com envoltório acelerou-se a partir de 90 horas.

O início da Fase III, tornando visível a retomada de crescimento do embrião, é identificada pela protrusão da raiz primária, no entanto, verificou-se, ao longo do período de observação, um retardamento na absorção de água em diásporos com envoltório em relação aos sem envoltório, não sendo observada a ocorrência da Fase III, provavelmente, devido ao fato do envoltório promover uma redução na velocidade de embebição. Nos diásporos sem envoltório o ganho de massa acelerou-se a partir de 105 horas, correspondente ao início da Fase III.

Quando as sementes escarificadas de $C$. brasiliense foram submetidas a diferentes regimes térmicos, verificou-se que nas temperaturas constantes de $10^{\circ} \mathrm{C}, 15^{\circ} \mathrm{C}$ e $40^{\circ} \mathrm{C}$ a germinação foi nula. Sementes a $10^{\circ} \mathrm{C}$ e $15^{\circ} \mathrm{C}$ não germinaram por estarem abaixo da temperatura mínima para a germinação da espécie. Após 30 dias as sementes que estavam a $10^{\circ} \mathrm{C} \mathrm{e} 15^{\circ} \mathrm{C}$ foram transferidas para a temperatura de $30^{\circ} \mathrm{C}$, atingindo valores de $53 \%$ e $65 \%$ de germinabilidade e IVG de 0,59 e 0,84, respectivamente, calculadas a partir do momento da transferência. As sementes de $C$. brasiliense, submetidas a $40^{\circ} \mathrm{C}$, por estarem acima da temperatura máxima para a germinação das sementes, provavelmente por terem sofrido danos irreversíveis, não germinaram quando transferidas para $30^{\circ} \mathrm{C}$. 


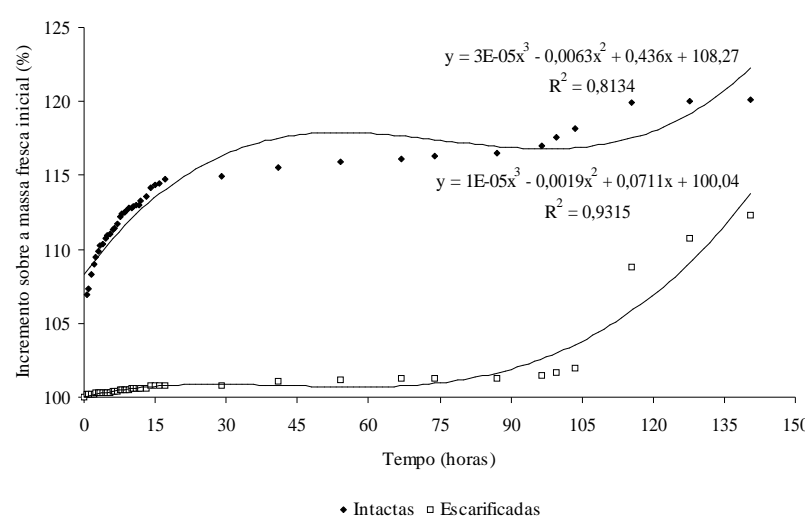

Figura 1 - Incremento em relação à massa fresca inicial (\%) de diásporos de $C$. brasiliense com e sem envoltório ao longo do período de embebição.

Resultados similares foram observados por Carvalho et al. (2001) para Sesamum indicum L., onde sementes incubadas em temperaturas subótimas apresentaram germinação elevada após transferência para a temperatura ótima $\left(30^{\circ} \mathrm{C}\right)$, enquanto as sementes incubadas em temperatura supra-ótima apresentaram relação inversa entre a germinação adicional após transferência e a temperatura inicial de incubação. Baixas temperaturas podem não somente reduzir a porcentagem de germinação, como também retardar o processo, por causa da redução das atividades enzimáticas envolvidas no metabolismo da semente (BEWLEY \& BLACK, 1994).

Assumindo que as sementes correspondem a um conjunto organizado de células cujo metabolismo depende essencialmente da atividade acoplada de diversas enzimas, seria esperado que, em determinadas temperaturas, a inativação de proteínas ocasionada por temperaturas extremas resultaria em um descompasso metabólico que comprometeria a germinação (MARCOS FILHO, 2005), isso pode, possivelmente, explicar a ausência de germinação de sementes de $C$. brasiliense submetidas a $40^{\circ} \mathrm{C}$.

Na tabela 1 observam-se os resultados das sementes escarificadas, submetidas a regimes térmicos, que apresentaram germinação. As sementes escarificadas exibiram porcentagem de germinabilidade superior nas temperaturas $30^{\circ} \mathrm{C}$ e $30 / 20^{\circ} \mathrm{C}$. Nota-se uma variação de $70 \%$ a $96 \%$ de germinabilidade entre os tratamentos estudados, sendo os menores valores de percentagens de germinabilidade encontrados para as temperaturas de $35^{\circ} \mathrm{C}$ e $25 / 15^{\circ} \mathrm{C}$.

Para o IVG, valores superiores foram encontrados para as temperaturas de $30^{\circ} \mathrm{C}$ e $35^{\circ} \mathrm{C}$ e o valor inferior encontrado para a temperatura de $25^{\circ} \mathrm{C}$ (Tabela 1).
Para o tempo médio de germinação $(\mathrm{Tm})$, valores inferiores foram apresentados por sementes submetidas às temperaturas $30^{\circ} \mathrm{C}, 35^{\circ} \mathrm{C}$ e $30 / 20^{\circ} \mathrm{C}$. Segundo Ferreira \& Borghetti (2004), as medidas de tempo médio de germinação podem ajudar a inferir que a germinação rápida é característica de espécies cuja estratégia é se estabelecer no ambiente o mais rápido possível ou quando oportuno, aproveitando condições ambientais favoráveis ao desenvolvimento do novo indivíduo.

Resultados semelhantes foram observados por Valeri et al. (2003) que, estudando o efeito do beneficiamento sobre a germinação e o vigor de sementes de $C$. brasiliense relataram que as sementes de frutos grandes e pequenos não apresentaram germinação quando intactos e que a maior germinação pôde ser observada em sementes nuas de frutos grandes, sob fotoperíodo de oito horas e temperatura alternada de $30 / 20^{\circ} \mathrm{C}$. Oliveira et al. (2005) relatou para sementes de Annona montana Macfad. que tanto a porcentagem de germinação como o IVG, os maiores valores observados foram na temperatura de $30^{\circ} \mathrm{C}$, seguido da temperatura de $25^{\circ} \mathrm{C}$, e nas temperaturas de $20^{\circ} \mathrm{C}$ e $35^{\circ} \mathrm{C}$ não foram observadas ocorrência de germinação.

A presença do tegumento não reduziu a percentagem final de germinação das sementes de $C$. brasiliense, não apresentando diferenças significativas entre os tratamentos. A temperatura também não afetou a germinação das sementes com e sem tegumento (Tabela 2).

Quanto ao IVG, nas sementes com tegumento não foram verificadas diferenças significativas entre as temperaturas e no tratamento sem tegumento; valores superiores de IVG foram encontrados para sementes submetidas a $30^{\circ} \mathrm{C}$. Não foram verificadas diferenças significativas nas sementes a $25^{\circ} \mathrm{C}$, com e sem tegumento e valores superiores de IVG foram obtidos pelas sementes a $20^{\circ} \mathrm{C}$ e $30^{\circ} \mathrm{C}$, ambas sem tegumento, demonstrando assim que o tegumento, possivelmente, dificulta a embebição de água pela semente retardando a germinação, mas não afetando a percentagem final de germinação (Tabela 2).

Foram observados para o $\mathrm{Tm}$, de modo geral que as sementes com tegumento tiveram germinação mais lenta do que as sementes sem tegumento, com diferença significativa para as temperaturas de $20^{\circ} \mathrm{C}$ e $30^{\circ} \mathrm{C}$ (Tabela 2).

Resultados similares aos obtidos neste trabalho, foram encontrados por Lima Júnior (2004) que, relatou para C. vernalis, que as sementes sem tegumento exibiram um percentual germinativo próximo ao máximo quando comparadas com as sementes intactas. Já para a espécie Cryptocarya aschersoniana Mez, Almeida (2001) não observou qualquer germinação de diásporos intactos, 
Tabela 1 - Valores médios de germinabilidade (\%), índice de velocidade de germinação (IVG) e tempo médio de germinação $(T m)$ (dias) de sementes escarificadas de C. brasiliense, submetidas a diferentes regimes térmicos.

\begin{tabular}{cccc}
\hline Temperaturas $\left({ }^{\circ} \mathrm{C}\right)$ & Germinabilidade $(\%)$ & IVG & Tm $($ dias $)$ \\
\hline 20 & $88,00 \mathrm{ab}$ & $1,98 \mathrm{bc}$ & $15,82 \mathrm{c}$ \\
25 & $75,00 \mathrm{bc}$ & $0,94 \mathrm{~d}$ & $27,79 \mathrm{a}$ \\
30 & $93,00 \mathrm{a}$ & $3,35 \mathrm{a}$ & $11,74 \mathrm{~d}$ \\
35 & $70,00 \mathrm{c}$ & $2,99 \mathrm{a}$ & $7,73 \mathrm{~d}$ \\
$25 / 15$ & $70,00 \mathrm{c}$ & $1,21 \mathrm{~cd}$ & $20,45 \mathrm{~b}$ \\
$30 / 20$ & $96,00 \mathrm{a}$ & $2,82 \mathrm{ab}$ & $9,61 \mathrm{~d}$ \\
\hline
\end{tabular}

*Médias seguidas pela mesma letra não diferem entre si, pelo teste de Tukey, a 5\% de probabilidade.

Tabela 2 - Valores médios de germinabilidade (\%), índice de velocidade de germinação (IVG) e tempo médio de germinação (Tm) (dias) de sementes de C. brasiliense, com e sem tegumento, submetidas a diferentes temperaturas.

\begin{tabular}{|c|c|c|}
\hline \multirow{2}{*}{ Temperaturas $\left({ }^{\circ} \mathrm{C}\right)$} & \multicolumn{2}{|c|}{ Germinabilidade (\%) } \\
\hline & Com tegumento & Sem tegumento \\
\hline 20 & $92 \mathrm{aA}$ & $88 \mathrm{aA}$ \\
\hline 25 & $89 \mathrm{aA}$ & $75 \mathrm{aA}$ \\
\hline \multirow[t]{2}{*}{30} & $84 \mathrm{aA}$ & $93 \mathrm{aA}$ \\
\hline & \multicolumn{2}{|c|}{ IVG } \\
\hline 20 & $0,99 \mathrm{aB}$ & $1,99 \mathrm{bA}$ \\
\hline 25 & $1,00 \mathrm{aA}$ & $0,95 \mathrm{cA}$ \\
\hline \multirow[t]{2}{*}{30} & $0,81 \mathrm{aB}$ & $3,35 \mathrm{aA}$ \\
\hline & \multicolumn{2}{|c|}{$T m$ (dias) } \\
\hline 20 & $33,46 \mathrm{aA}$ & $15,82 \mathrm{bB}$ \\
\hline 25 & $28,15 \mathrm{aA}$ & 27,79 aA \\
\hline 30 & $30,62 \mathrm{aA}$ & $11,74 \mathrm{bB}$ \\
\hline
\end{tabular}

*Letras minúsculas nas colunas e maiúsculas nas linhas, dentro de cada fator, não diferem siginificativamente entre si, pelo teste de Tukey, a $5 \%$ de probabilidade.

apenas aqueles que foram escarificados apresentaram germinação aos 28 dias de avaliação, inferindo que a retirada do endosperma desses diásporos constitui fator essencial para a sua germinação. Para Ocotea odorifera, a remoção do envoltório (endocarpo e tegumento) promoveu maior velocidade e porcentagem de germinação nas temperaturas de $25^{\circ} \mathrm{C}$ e $30^{\circ} \mathrm{C}$ (CETNARSKI FILHO \& NOGUEIRA, 2005).

A entrada de água nas sementes de $C$. brasiliense tem sua velocidade reduzida pelo tegumento, porém a germinabilidade total não foi afetada. Considerou-se $30^{\circ} \mathrm{C}$ como a temperatura ótima de germinação, por ter apresentado maior percentagem de germinação total, valor superior de IVG e menor $T m$. Temperaturas baixas inibem a germinação, mas não causam danos irreversíveis às sementes. Temperatura elevada $\left(40^{\circ} \mathrm{C}\right)$ é deletéria para as sementes, inibindo a germinação.

\section{REFERÊNCIAS BIBLIOGRÁFICAS}

ALMEIDA, L. P. Germinação, crescimento inicial e anatomia foliar de plantas jovens de Cryptocarya aschersoniana Mez. sob diferentes níveis de radiação. 2001. 96 p. Dissertação (Mestrado em Agronomia. Fisiologia Vegetal) - Universidade Federal de Lavras, Lavras, 2001.

BEWLEY, J. D.; BLACK, M. Physiology and biochemistry of seed in relation to germination. Berlin: Springer Verlag, 1978. v. 1, 306 p. 
BEWLEY, J. D.; BLACK, M. Seeds: physiology of development and germination. New York: Plenum, 1994 $445 \mathrm{p}$.

BORGHETTI, F. Ecofisiologia da germinação das sementes. Universa, Brasília, v. 8, n. 1, p. 149-180, 2000.

BRASIL. Ministério da Agricultura. Regras para análise de sementes. Brasília, DF, 1992. 365 p.

CARVALHO, N. M.; NAKAGAWA, J. Sementes: ciência tecnologia e produção. Jaboticabal: FUNEP, 2000. 588 p.

CARVALHO, P. E. R. Espécies florestais brasileiras: recomendações silviculturais potencialidades e uso da madeira. Colombo: Embrapa/CNPF; Brasília, DF: Embrapa/ SPI, 1994. 640 p.

CARVALHO, P. G. B. de; BORGHETTI, F.; BUCKERIDGE, M. S.; MORHY, L.; FERREIRA-FILHO, E. X. Temperaturedependent germination and endo-b-mannanase activity in sesame seeds. Revista Brasileira de Fisiologia Vegetal, Londrina, v. 13, n. 2, p. 139-148, 2001.

CETNARSKI, R. F.; NOGUEIRA, A. C. Influência da temperatura na germinação de diásporos de Ocotea odorífera (Vellozo) Rohwer (Canela-sassafrás). Ciência Florestal, Santa Maria, v. 15, n. 2, p. 191-198, 2005.

FERRAZ-GRANDE, F. G. A.; TAKAKI, M. Temperature dependent seed germination of Dalbergia nigra Allem (Leguminosae). Brazilian Archives of Biology and Technology, Curitiba, v. 44, n. 4, p. 401-404, 2001.

FERREIRA, A. G.; BORGHETTI, F. Germinação: do básico ao aplicado. Porto Alegre: Artmed, 2004. 323 p.

FLORES, E. M. Calophyllum brasiliense Cambess. In:VOZZO, J. A. (Ed.). Tropical tree seed manual. Washington: USDA Forest Service, 2002. p. 353-356. (Agriculture Handbook, 721).

LABOURIAU, L. G. A germinação da semente. Washington: OEA, 1983. $173 \mathrm{p}$.

LIMA JÚNIOR, E. C. Germinação, armazenamento de sementes e fisioanatomia de plantas jovens de Cupania vernalis Camb. 2004. 115 p. Dissertação (Mestrado em
Agronomia - Fisiologia Vegetal) - Universidade Federal de Lavras, Lavras, 2004.

MAGUIRE, J. D. Speed of germination: aid in selection and evaluation for seedling emergence and vigor. Crop Science, Madison, v. 2, n. 2, p. 176-177, 1962.

MARCOS FILHO, J. Fisiologia de sementes de plantas cultivadas. Piracicaba: Fealq, 2005. 495 p.

MEDEIROS-SILVA, L. M. de; RODRIGUES, T. de J. D.; AGUIAR, I. B. de. Efeito da luz e da temperatura na germinação de sementes de aroeira (Myracrodruon urundeuva Allemão). Revista Árvore, Viçosa, v. 26, n. 6, p. 691-697, 2002.

OLIVEIRA, I. V. de M.; ANDRADE, R. A. de; MARTINS, A. B. G. Influência da temperatura na germinação de sementes de Annona montana. Revista Brasileira de Fruticultura, Jaboticabal, v. 27, n. 2, p. 344-345, 2005. (Comunicação técnica).

POPINIGIS, F. Fisiologia da semente. Brasília, DF: Agiplan, 1985. 289 p.

SANTANA, D. G. de; RANAL, M. A. Análise estatística. In: FERREIRA, G. A.; BORGHETTI, F. Germinação: do básico ao aplicado. Porto Alegre: Artmed, 2004. p. 197-208.

SANTOS, S. R. G. dos. Efeito da temperatura na germinação de sementes de Sebastiana commersoniana (Baill.) Smith e Downs (Branquilho). 1999. 76 f. Dissertação (Mestrado em Agronomia - Produção e Tecnologia de Sementes) Universidade Estadual Paulista, Jaboticabal, 1999.

SAS INSTITUTE. SAS/STAT user guide. 4. ed. Cary, 1990.

SOCOLOWSKI, F.; TAKAKI, M. Germination of Jacaranda mimosifolia (D. Don - Bignoniaceae) seeds: effects of light, temperature and water stress. Brazilian Archives of Biology and Technology, Curitiba, v. 47, n. 5, p. 785-792, 2004.

VALERI, S. V.; VASCONCELOS, M. T. de; PAULA, R. C. de; MASSI, K. G. Germinação e vigor de sementes de guanandi (Calophyllum brasiliense) submetidas a diferentes formas de beneficiamento. Informativo Abrates, Londrina, v. 13, n. 3, p. 404, 2003. 